\title{
Cantantes peruanos de bolero
}

Peruvian bolero singers

\author{
Manuel Zanutelli-Rosas ${ }^{1}$
}

\section{Resumen}

Con un estilo periodístico, el autor nos presenta una síntesis biográfica de los cantantes de bolero que estuvieron de moda en nuestro país entre 1950 y 1970. El bolero es un género musical de letra simple, lastimera y llorona que nos canta el desamor, el amor imposible, el amor frustrado, la pasión de amar, la obsesión por amar y la esperanza por amar.

Palabras claves: canción, música, bolero.

\begin{abstract}
With a journalistic style, the author presents a biographical synthesis of bolero singers who were in fashion in our country between 1950 and 1970 . Bolero is a musical genre of simple lyrics, plaintive and weeping that sings to us the heartbreak, the impossible love, the frustrated love, the passion to love, the obsession to love and the hope to love.
\end{abstract}

Keywords: Song, music, bolero.

Periodista y escritor.

\section{Lucho Barrios y EI Bolero Cantinero (1935-2010)}

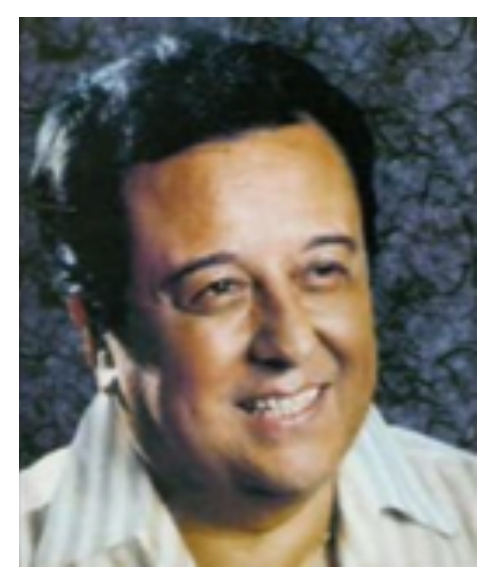

A continuación, se presenta una relación de los más connotados boleristas que hicieron historia en el medio musical peruano entre los años de $1950 \mathrm{y}$ 1970.

El bolero vino de México, lento, sabrosón, para bailarlo pegadito. Así arribó, en esas películas de pobre argumento, con Pedro Vargas, ese señor que se inclinaba tres veces y respondía los aplausos con un ceremonioso: "Muy agradecido, muy agradecido, muy agradecido" y también con Toña la Negra y María Luisa Landín. 
Las rockolas, de los bares y cantinas, llamadas también sinfonolas, dejaban escuchar sus canciones de esquina en esquina, de plazuela en plazuela; se difundían sus letras de amor incomprendido, expresiones de lamentables derrotas, como testimonio de los vencidos.

El bolero se escuchaba por todas partes: en los discos MAG, de pizarra de 78 revoluciones, muy frágiles. En los hogares en el modesto pick-up de agujas cambiables; y en lugares nada santos, en una rockola.

Rondando tu Esquina. Digamos que era la esquina de Lucho Barrios, el lugar estratégico de la espera trascendente, significativa en sus recuerdos:

Esta noche tengo ganas de buscarla, de olvidar lo que ha pasado y perdonarla, ya no me importa el qué dirán, ni las cosas que hablarán, toda la gente siempre habla

Me engañas mujer. Se bailaba entre copa y copa, entre trago y trago porque en cada uno de sus versos estaba el recuerdo de la mujer que se amó:

\section{Me engañas mujer \\ con el mejor de mis amigos que fue como un hermano, con él te encontré y a los dos perdoné}

En los bares del Callao, los boleros eran los favoritos de las copetineras y los badulaques en plan de diversión. No quiere decir que se excluyeran otros ritmos -el boogie boogie, el foxtrot y el tango, porque allí estaban los fieles seguidores.

Se difundían "Copas de licor", "Amor de pobre", "Brujerías" y tantos otros. Era su hora cenital, su momento cumbre.

Lucho había sido muchacho de barrio; cinemero de locales pobretes a los que acudía con la patota de su calle.
Cuando se fue a vivir a Lima se convirtió en un chalaco adoptado por los Barrios Altos. Como cada ave busca la de su pluma, se casó con la cantautora Zenobia Cáceres Sánchez y tuvieron dos hijos: Luis y Armando, y enamorado del amor enlazó su vida a la de María Arauz, de nacionalidad ecuatoriana. Mas, pertinaz conquistador, sería padre de una niña de nombre Milagros, hija de Elsa Espejo, ex funcionaria de Radio San Isidro. Para ubicarse en un lugar del cancionero había remado mucho. Su público era el vecindario que lo admiraba, lo aplaudía y nunca dejó de alentarlo. Su potente y modulada voz causaba favorable impresión.

En Hispanoamérica sería el referente del llamado "bolero cantinero". En 1960 actuó en Arica y se hizo popular con "Marabú", el bolero que lo identificaría.
Adiós, ya me quedo sin ti, y asi para qué más vivir.
Sin ti, no podré más luchar, sin ti para qué resistir.
No sé para qué quiero amor,
la esperanza sin $t i$,
ya no tiene valor.

Edith Barr lo ayudó en sus inicios con lo que estaba a su alcance: lo llevó a Radio Callao en la mejor época de esa entrañable emisora y allí conoció al ecuatoriano Julio Jaramillo, quien lo invitó a visitar su país.

Uno de sus maestros fue el musicólogo Alejandro Vivanco, hermano del esposo de Ima Sumac. Y, como logró forjarse un nombre las puertas de las disqueras IEMPSA y Sono Radio se abrieron para él. Fue tanta su compenetración mediante la música con los pobladores de todos los estratos sociales, que obtuvo el reconocimiento de la Organización de Estados Americanos (OEA) por haber contribuido con su canto al "acercamiento de los pueblos".

Los años pasaron y al recuperarse de una enfermedad retornó a los escenarios, pero fue una vuelta que trajo 
cola. Ya estaba viejo, con una vejez enormemente debilitada por toda una existencia de malas noches y quizá por las copas de licor, de los brindis un día hoy y otro mañana.

Su estado de salud volvió a causar preocupación en su hogar. Los médicos le recomendaron descanso y un necesario cambio de vida, porque sus actividades estaban causándole, por intensas, un serio deterioro a la salud.

El triste y lamentable fin: el 3 de mayo del 2010 se derrumbó, se puso mal y lo condujeron al Hospital Dos de Mayo y tres días después falleció a las 7.30 de la mañana. Diagnóstico: falla multisistémica o síndrome de disfunción multiorgánica. Sus restos fueron velados en el Museo de la Nación.

¡Adiós, gran cantante, adiós bolerista, adiós a las neblinosas madrugadas del traicionero invierno limeño! ¡Adiós, Marabú!

\section{Pedro Otiniano (1937-2012)}

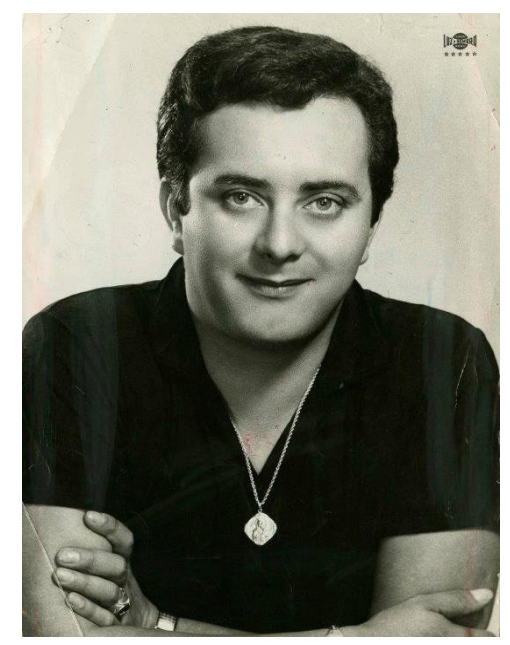

Otiniano, nacido en 1937, se inició en Radio Mundial cantando valses como "Fatalidad" de Laureano Martínez. Su voz clara y rotunda llamó la atención y se pensó en un nuevo valor del cantar popular peruano. Pero se haría famoso, al menos en nuestro ambiente, como intérprete de boleros.
Muy pocos como él expresaban con tanta pasión la música cantinera en un contexto suburbano con letras de arrebato y desborde sentimental. En igual nivel estuvo Lucho Barrios.

Toda su existencia la ofreció a la música, sin temor a los amaneceres ni a la traicionera garúa limeña, ni al viento helado del invierno.

Ganó aplausos y dinero con "Cinco centavitos", "Ay, cariño", "Que te vaya bien". Los discos de 45 se escuchaban por todas partes, especialmente en los bares donde las rockolas eran las reinas de la noche.

¡Ay! cariño,

Si vieras cómo estoy desesperado

Por tu ausencia

Soñando a cada instante con la luz

De tu presencia

Llamándote en mis noches y llorando como un niño

¡Ay! cariño,

¡Ay cariño

Estaban ya lejanos los años en que entretenía a los socios del Club de La Unión, en la sobremesa de los almuerzos sabatinos o domingueros y en las noches de celebraciones familiares. Hay que decirlo: marcó toda una época, hizo soñar a las muchachas románticas y emborracharse a los enamorados $\mathrm{o}$ novios frustrados.

Así como todo tiene un comienzo, todo igualmente tiene un final; y éste llegó el 2 de agosto del 2012, a los 75 años, cuando era un anciano y sus amigos habían emprendido el misterioso viaje de la muerte. La noticia no sorprendió a nadie, porque había estado internado en el Hospital Guillermo Almenara durante cuatro meses luchando por su sobrevivencia. Se supo entonces que "una falla multiorgánica" lo derrumbó.

La fatal obesidad extremada o "gordura mórbida" 
que padeció también el "Zambo Cavero" con tan fatales consecuencias, le quebró la existencia.

\section{Rosa Palma Gutiérrez Fetiche (1928-2005)}

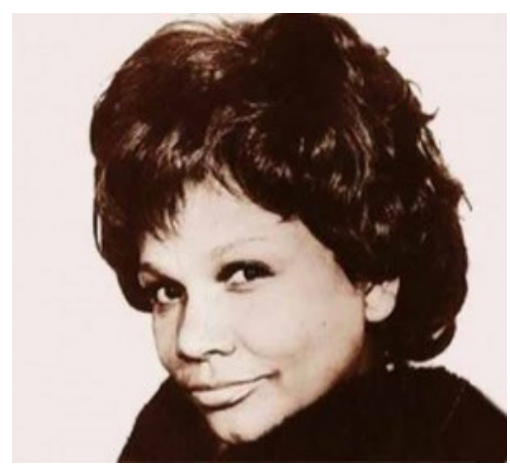

Adoptó el seudónimo de Fetiche. Cantante de música tropical nacida en el Callao en 1928. En su primera etapa interpretó canciones nuestras, pero después, cuando viajó a México y Argentina, incluyó música internacional, sobre todo boleros y, en algunas oportunidades tangos, tan populares en los años 50.

Otro escenario en Lima fue la televisión en blanco y negro. Pasó los años de vejez en Barranco, en unión de su familia y falleció a los 77 años. Fue como una hermana mayor, guía y ejemplo para las cantantes que llegaron después.

\section{Lina Panchano (1940-2009)}

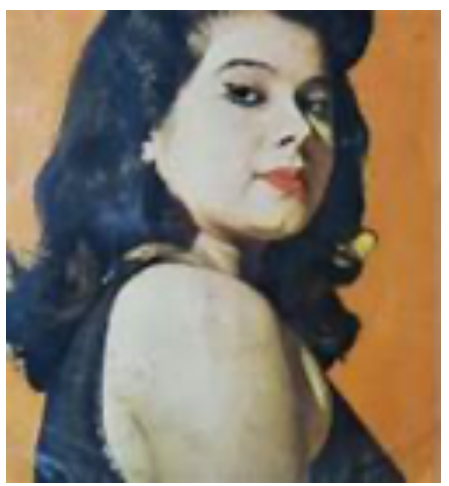

Era barrioaltina, criolla de cuna y vida. En los años 1960's su participación en un certamen publicitado por una firma comercial en el Canal 4 le abrió el camino a la popularidad. A partir de entonces actuó también en locales nocturnos.

Un bolero, "Cataclismo", que expresaba con una fuerza emotiva y contagiosa, consolidó su nombre e imagen como artista del espectáculo.

¿Qué pasará si tú me dejas?

¿Qué pasará si tú me olvidas?

Le he preguntado a las estrellas

A la luna

Otros boleros, bolerazos, afianzaron su presencia en el mundo de la música.

Odio en la Sangre:

No me mires más

Que me haces daño

No me interesa

Ya tu cariño

Tú eres mala hembra

No tienes alma

Tú no mereces

Que nadie te quiera

Estas canciones de muy pobre letra era lo que tenían y con ellas trabajaban. El éxito estuvo en su voz, en la interpretación, porque su trivialidad literaria es absoluta.

Sin embargo, los géneros musicales cambian con el tiempo, se agotan y hasta se esfuman, como pasó con el mambo de Dámaso Pérez Prado, que llegó a conquistar Hollywood y escenarios europeos. O sucedió incluso con la rumba y la guaracha.

Este paréntesis, quizá de desconcierto para algunos, era necesario llenarlo y eso fue lo que hizo Lina, quien como solista llegó a ser la portavoz de la Cumbia Peruana. Animó las veladas del entonces restaurant "El Tumi", que estaba de moda. Pero los años, como los ríos, transcurren, pasan, y a Lina Panchano le llegó la vejez, o digamos mejor la ancianía, y el 16 de enero del 2009, a los 69 años, nos dejó con sus recuerdos, su música y, en conjunto, con su humanísimo perfil. 


\section{Vicky Zamora "La Guarachera del Perú"} (1940-)

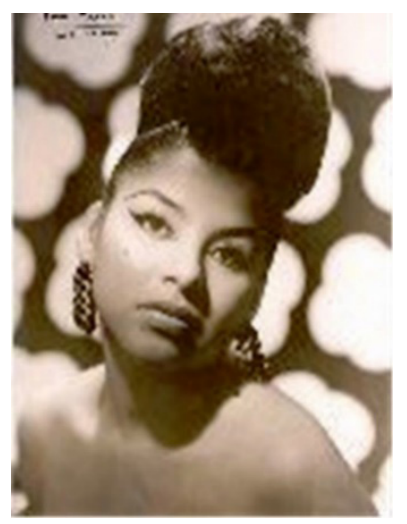

Nació en Miraflores el 20 de octubre de 1940. Muy joven contrajo matrimonio con el odontólogo Carlos Manrique Escobar, fundador de la Sonora Capri.

Vicky Zamora formó parte de la Sonora de Nico Estrada. Grabó con Lucho Macedo, la Sonora Sensación que dirigía Mario Cavagnaro. Cantó en el Grill del Hotel Bolívar y en el canal 13 TV.

Pasó su juventud como vecina de la calle Belén y como cantante viajó al extranjero. Al retornar, nostálgica, decidió caminar por su antigua calle, donde estaba Radio Central y en el mismo local Radio Libertad. No encontró nada. Retornó a Europa y radicó en España. En las oportunidades que venía de vacaciones recorría las calles del centro en el afán imposible de recuperar la imagen del pasado.

Fue Lady Crooner en la Lecuona Cuban Boys, en la época -brillante época- de la guaracha y la rumba a las que después se agregaron el mambo y el insípido Cha-cha-cha, que solo fue afortunadamente ave de paso.

En una de sus giras arribó a Finlandia y su sorpresa fue grande cuando se encontró nada menos que con la bailarina de los años 50 Anakaona. Y también, en otra ocasión, vio cantar al showman peruano Mario Gensollén.
Anakaona con Betty di Roma y la monumental Mara llenaban los teatros de Lima, con los bailes sensacionales del Cara re foca Dámaso Pérez Prado: el mambo, que en los años 50 se escuchaba en los discos de pizarra.

Divorciada, contrajo matrimonio con un ingeniero alemán y por esa razón dejó la vida artística, la música retumbante y alegre del Caribe y consagró su tiempo y su vida a sus dos hijas. Quienes conocen algo más de esta recordada cantante, expresaron que respondieron a la educación y cuidado que les dieron sus padres. Ahora una es concertista de piano y la otra pintora.

\section{Anamelba (1942-2011)}

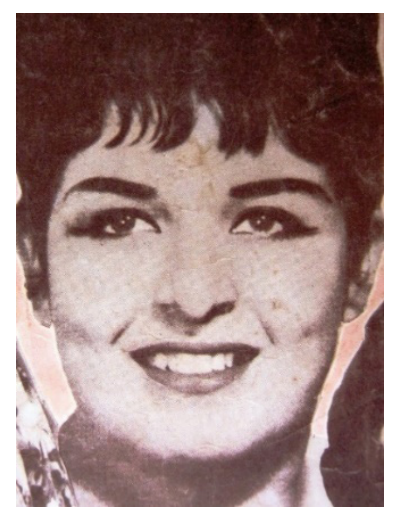

Destacó desde 1961 en el conjunto "Los Kipus" que dirigía el guitarrista Paco Maceda, pero cuando empezó a actuar como solista adoptó el seudónimo de Anamelba. Su verdadero patronímico fue el de Melba Annie Pinzás Salazar. Su voz era clara, vibrante, potente. Tenía el título de docente en danzas folclóricas.

Durante los viajes a Lima del ecuatoriano Julio Jaramillo, iniciaron una relación que consolidaron con el matrimonio en 1957 y tuvieron una hija, bautizada como Anamelba del Rocío Jaramillo Pinzás. Fue una relación que duró solo un año. 
Gaby Zevallos (1944-2016)

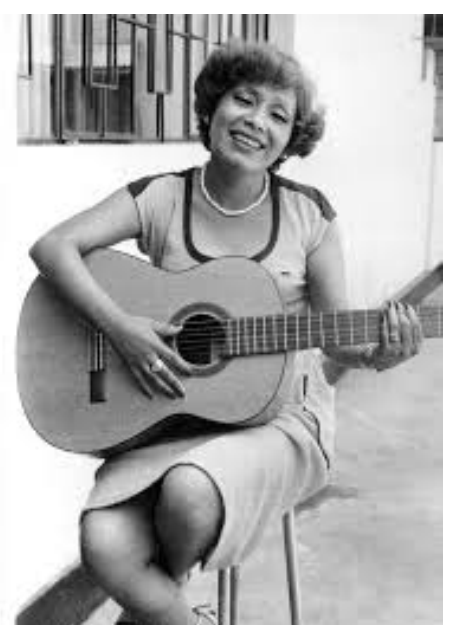

Era chalaca, nacida en 1944, cuatro años después del terremoto que acabó con más de la mitad de edificaciones del primer puerto. Criolla en el gusto por la comida y las costumbres, criolla en el decir, no cantó sin embargo nuestra música.

Uno de sus temas más celebrados fue "Corazón herido".

\section{Este cariño que siento por ti}

no lo he sentido por nadie jamás,

tú tienes algo que me hace sentir,

algo que nadie me hizo vivir.

Una mirada me diste al partir,

fue como un rayo de felicidad;

tú me has herido en el corazón,

como la flecha que hiere al amor.

Letra simple, de lugares comunes, con versos llorones; el clásico bolero que tuvo seguidores.

Dejó de existir en julio del 2016. Vivía en el distrito de San Miguel.

\section{Linda Lorenz (1945-)}

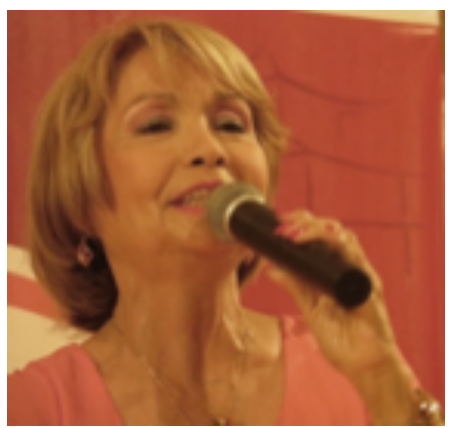

Linda Lorenz era el nombre artístico de Imelda Angélica Santaya Fuente, nacida en 1945, en Yurimaguas, provincia del Alto Amazonas, departamento de Loreto). Fue llamada "La voz del bolero".

Era una romántica que se apoderaba de los escenarios con su voz siempre limpia que la condujo a Nueva York para gozo y contento de la comunidad latina. "Cárcel de Amor" fue como la nave insignia de su repertorio. Era poseedora de una discografía que incluye LP, mini LP y los modestos $45 \mathrm{rpm}$.

Cuando retornó a su tierra con motivo del 144 aniversario de la creación política del Alto Amazonas, invitada por el municipio, se le impuso la Medalla de Honor de la provincia.

En Lima cantaba en el restaurant "El Palmero" de la Residencial San Felipe, y como ella, Los Zañartu, cuarteto integrado por los hermanos Julissa, Elena, Luis y Antonio Zañartu. Actuaban también Roberto Silva y Vicky Rodríguez. El director musical fue Lucho Neves. Ha grabado además "Niégalo", "Encadenados", "Tú sabes", "Osito de felpa", "Ruegos vanos". Desempeñó labor docente. Tiene 76 años. 
Vicky Jiménez (1953-)

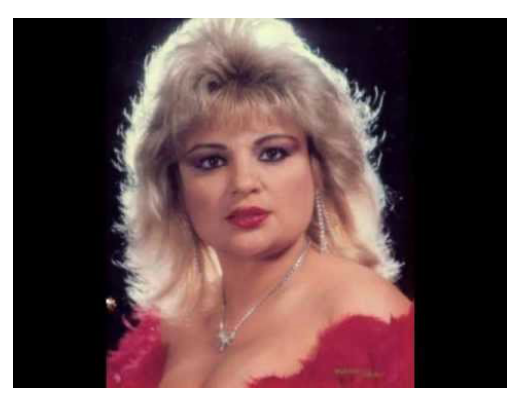

Es (o era) poseedora del trofeo Circe que otorgaba el Círculo de Cronistas del Espectáculo, tres Discos de Oro y dos Discos de Platino por el éxito de ventas obtenido internacionalmente con sus canciones. Vicky Jiménez es su nombre artístico, el verdadero es Ana maría Gastañeta García; grabó veinte LP, setenta discos de $45 \mathrm{rpm}$ y diez CD que se vendieron en América Latina y Europa. Nació el 9 de febrero de 1953.

Inició su carrera en 1979. Su alto registro vocal le abrió una etapa en el arte lírico. El antecedente en este aspecto es su tía Ana María Parodi, considerada la primera soprano del Perú.
Paseó su voz como Lady Crooner de la Sonora Matancera del legendario Rogelio Martínez; y considerada la "reina del bolero", se mantuvo vigente hasta noviembre del 2013.

Radica en los Estados Unidos, en la ciudad de California, convencida de haber cumplido su tarea artística que le dio tantas satisfacciones.

De esta manera, hemos querido recordar a los que tenemos cierto número de años de vida aquellos inolvidables cantantes de bolero del Perú.

\section{Correspondencia:}

Manuel Zanutelli

manuel.zanutelli@yahoo.com

Fecha de recepción: 01-07-2021.

Fecha de aceptación: 20-08-2021.

Conflicto de interés: Ninguno, según el autor.

Financiamiento: por el autor. 